Research, part of a Special Feature on The Governance of Adaptation

\title{
The Influence of Forums and Multilevel Governance on the Climate Adaptation Practices of Australian Organizations
}

\author{
Lorraine E. Bates $^{1}, \underline{\text { Melissa Green }}^{1}$, Rosemary Leonard ${ }^{1}$ and Iain Walker $^{1}$
}

ABSTRACT. To date, there are few regulations and policies relating to climate change in Australia. Uncertainty about the timing, structure, and potential impact of proposed legislation such as a national carbon abatement scheme, is leading to planning delays across the country. To assist with these policy uncertainties, organizations can embed themselves in multilevel governance frameworks that inform, structure, and facilitate strategic development, planning, and action. As part of these networks, organizational representatives also engage in formal and informal forums, a type of interorganizational relationship, which can include industry task forces, policy development committees, interagency groups, and specific climate change committees. Forums constitute an additional level of governance that influences decision making.

The patterns of relationships within these multilevel governance frameworks are examined in this paper, with a focus on the forum level of organizational cooperation. Specifically, we investigate the type of forums operating and their role in supporting organizational responses to climate change. A series of interviews and focus groups were conducted in two study areas, the Swan Canning region of Western Australia and the Hunter / Central Coast region of New South Wales. The results indicate that organizations participate in a diverse range of forums. Further, forums appear to play a key role in the everyday business of organizations by enhancing their ability to plan and address a range of issues, including those associated with climate change. In addition the research highlights some of the barriers and drivers for the development and implementation of climate adaptation practices that emerge from forum discussions. For example, a lack of government guidance in interpreting climate change policy was described as a barrier yet access to the knowledge and expertise of participants was highlighted as a potential driver. The paper discusses how an ability to create new forums and utilize existing nonclimate related forums assists organizations in addressing climate change impacts. We contend that forums constitute a level of governance deeply embedded in organizational practice that influences both their capacity and motivation to undertake climate adaptation. Our findings suggest that research investigating the rules that govern forums and the structural properties of the networks in which they are embedded is required to further understand the role of multilevel governance in shaping organizational responses to climate change.

Key Words: climate adaptation; climate change; decision making; forums; multilevel governance; networks; organization

\section{INTRODUCTION}

The more incontrovertible climate change science becomes the greater the prominence of the issue in the eyes of the public. The potential risks and impacts impinge on every aspect of society. Perceptions of the risks, along with individual and collective capacities to respond to the challenges of climate change are topics of scientific and community debate (Whitmarsh and Lorenzoni 2010). Although effects and responses will differ from sector to sector, organizations represent important components of society and face new challenges and opportunities from climate change (Winn et al. 2011, Berkhout 2012). Responses to climate change are typically grouped into two categories. Mitigation involves reducing emissions or enhancing greenhouse gas sinks; and adaptation considers adjustments in natural or human systems in response to anticipated or actual changes in climatic conditions (IPCC 2001).

Adaptation actions are framed in the context of international politics, national and local governments, firms, nongovernmental organizations, and households involving multiple societal levels (Paavola 2008) that are embedded in multilevel governance frameworks. We align our interpretation of governance with that of Moser (2009), to encompass the decisions, processes, institutions, mechanisms, norms, and authority underlying actions; and Folke et al. (2005:444) where governance represents "the structures and processes by which people in societies make decisions and share power." Reed and Bruyneel (2010:648) describe multilevel governance systems as "systems that are linked horizontally (across geographic space) as well as vertically (across levels of organizations)." Bache and Flinders (2004:v) suggest that multilevel governance systems explain "the dispersion of central government authority both vertically to actors located at other territorial levels, and horizontally to non-state actors." We contend that forums act as venues supporting the dynamic cross-scale and cross-level interactions that facilitate effective environmental management that Cash et al. (2006) describe. Little research has been conducted to examine how forum activity impacts on decision making and climate adaptation practice within multilevel governance systems. 
Adaptation to climate change involves complex environmental resource governance, embodying the regime characteristics identified by Pahl-Wostl (2009):

Institutions and the relationship and relative
importance of formal and informal institutions.
Actor networks with emphasis on the role and
interactions of state and non-state actors.
Multilevel interactions across administrative
boundaries and vertical integration.
Governance modes - bureaucratic hierarchies,
markets, networks (Pahl-Wostl 2009:356).

This analytical framework has been utilized in numerous resource management domains particularly water management (Knuppe and Pahl-Wostl 2011, Pahl-Wostl et al. 2012). Adaptive multilevel governance systems that:

... facilitate learning and adaptation in complex
social-ecological circumstances,... connect community
based management with regional/national government-
level management, link scientific management and
traditional management systems, encourage the
sharing of knowledge and information, and promote
collaboration and dialogue around goals and
outcomes (Armitage 2008:8)

... are of particular relevance in efforts to address climate change.

However, despite the advantages of involving numerous and varied actors, a high level of involvement is difficult to achieve and many ongoing problems can be attributed to governance failures (Pahl-Wostl 2009). Diversification is likely to lead to issues around responsibility, accountability, and delays in reaching consensus (Bulkeley and Moser 2007). An inability to address issues can result from governance structures that lack efficiency and effectiveness, or are overregulated (PahlWostl 2009).

Despite these challenges, it is likely that effective, modest systems that do not require the involvement of numerous highly diverse actors are achievable. In our research the potential and nature of multilevel governance systems and the part played by forums in facilitating responses to climate change are studied for two types of organizations, local government and businesses.

\section{The role of the public sector}

Governments play an essential and direct role in climate change by influencing other organizations through legislation of incentives and penalties. In Australia governments operate at federal, state, and local levels and although efforts to address climate change issues occur at each of these levels, local government, in particular, is considered to be at the forefront (Scott and Weston 2011).
At both the federal and state level most efforts focus on mitigation rather than adaptation. At the federal level attempts have been made to control carbon emissions through legislation while less controversial programs feature initiatives with local communities to encourage carbon reduction, energy efficiency, and climate adaptation. Examples include the Low Carbon Communities Program (Australian Government Department of Climate Change and Energy Efficiency 2012a) and the Cities for Climate Protection (CCP) Australia program (Australian Government Department of Sustainability Environment Water Population and Communities 2012).

At the state level, initiatives tend to focus on energy efficiency like the Environmental Upgrade Agreement in New South Wales (NSW Government Department of Environment and Heritage 2012) and the Low Emissions Energy Development Fund of Western Australia (Government of Western Australia Department of Environment and Conservation 2012). These states also provide support to conservation groups active in climate change communication and response.

Local government councils vary widely in size, from around 30 staff to more than 1000 , with coincident variability in resources and capacity to support initiatives. However, local governments do have access to incentives offered by the federal government and some state governments. Taking up opportunities such as the Local Adaptation Pathways Program (LAPP) has enabled significant improvements in the capacity of local councils to take a more strategic approach to climate change and share what they have learned (Australian Government Department of Climate Change and Energy Efficiency 2012b).

A number of activities take place in our study areas that are relevant when assessing climate adaptation practices among organizations because they raise awareness of climate change issues and stimulate interorganizational discussion. The federal initiative, Smart Grid, Smart City is a consortium of government, industry, and education sectors established to create a more efficient, more intelligent electricity supply for the future (Australian Government Department of Resources Energy and Tourism 2012). Two local governments in our NSW study area, Newcastle and Lake Macquarie City Councils, are partners. The Hunter Central Coast Regional Environmental Management System (HCCREMS) includes all local government councils in our study area. This group coordinates and targets regionally based climate change research and information outreach programs (HCCREMS 2012).

In Western Australia the WA Local Government Association provides support for local government through a toolkit that includes a process to assist councils to develop a climate adaptation strategy (WALGA 2012). Councils in WA are also 
able to apply for funding under federal government initiatives like the Energy Efficiency Program. In addition to benefitting from these programs, some local councils in our west coast study area operate small schemes for the benefit of their constituents.

Strategic planning and action on mitigation and adaptation is of particular relevance for local government because they are closest to the community and most likely to experience pressure from constituents. They are also responsible for many on ground environmental management issues. Furthermore, local government may well be exposed to litigation associated with zoning decisions and construction approvals given climate projections and risks from floods and sea level rise (Abel et al. 2011, Baker and McKenzie 2011, Gurran et al. 2011).

\section{Responses of business organizations}

Equivocation is a common organizational response in the face of climate change pressure in Australia. This circumspection may be understandable given the level of uncertainty and lack of guidelines on climate change. Uncertainty revolves around the potential impact of climate change, as well as the likely impact of policies targeting emissions. The ability of businesses to respond depends in part on size. Small enterprises, fewer than 20 employees, and medium enterprises, between 20 and 200 employees (Australian Bureau of Statistics 2002) tend to concentrate on daily activities (Studer et al. 2008), focusing their constrained resources on core business concerns (Biondi et al. 2000) because they perceive few benefits from engaging with environmental issues (Brammer et al. 2012). Together with increasing business costs, these factors may lead to inaction on preplanning, and a lack of strategic restructuring to better position individual organizations. However, Easterling et al. (2004) suggest that a 'wait and see' attitude has the potential to be very costly, given the possibility of inappropriate development decisions and the legacy of long term infrastructure investments that are expensive to modify.

The principal preoccupation of many Australian businesses has been the impact of the Clean Energy Future Legislation on their companies and the competiveness of the Australian economy. Although the legislation took more than six years to pass into law, to date, many organizations remain unprepared.

\section{Organizational interaction via forums}

An effective regulatory framework is a necessary but insufficient condition for achieving the goals of legislation because the politics of climate change risk is not confined to the formal political system. A wide network of organizations, institutions, and individuals are involved in negotiations to define and contest liability, obligations, and responsibility. Organizations can be defined as "the social entities ... created to accomplish tasks" whereas institutions are the formal regulations and informal "cultural norms, values, and accepted practices that govern how behaviors in and between these organizations takes place" (Matthews and Sydneysmith 2010:231).

When investigating the perceptions of state energy policy experts on wind energy deployment in four states of the USA, Fischlein et al. (2010) found that success was shaped by statelevel socio-political context and economic factors. Maggioni et al. (2012) examined the effectiveness of Climate Action Plans developed to mitigate greenhouse gas emissions by formal climate change committees in 18 states of the USA. Stakeholders were drawn from the energy sector. Their research highlights earlier findings showing the importance of understanding how structural characteristics particularly power relationships, incentives, and motivations of stakeholders influence policy recommendations (Agranoff 2006, Bidwell and Ryan 2006, Ansell and Gash 2008). Thus local partnerships, policy networks, and informal and formal collaborative mechanisms may play a role in compliance by providing more strategic choices (Scholz and Wang 2006). Smith et al. (2011) echo this idea suggesting that Australia can change how climate change issues are addressed by focusing on transdisciplinary and emerging fields of scientific research, and by continuing to include all tiers of government, industry, and communities of place and interest.

Forums represent a type of interorganizational relationship typical of multilevel governance frameworks and constitute an avenue for organizations "to solve complex mutual problems, to stay attuned with what their competitors are doing and/or influence their industry to undertake a particular course of action or inaction" (Bates et al. 2011:8). They include senior officers meetings, interagency task forces, senior advisory committees, professional conferences, and public/private planning processes among others. Forums can include businesses, not-for-profit and governmental organizations. They may be specific to a particular type of organization or industry or be broadly inclusive. Forums may be developed specifically to address climate change issues or to address a range of member concerns that might include climate change issues.

Professional forums or meetings held on a regular or semiregular basis represent the primary mechanism through which many relationships are forged and maintained. Informal associations facilitated by these forums provide additional opportunities for interaction and may influence organizational perceptions of threats and opportunities associated with climate change. Over time, these relationships may become stronger and fulfill many functions like advice seeking, consensus building, normative guidance, lobbying, protocol formation, reinforcement, and promotion. Forums are often considered in conjunction with arenas of interaction, which represent different domains of actor activity such as 
organizations, regions, and governance levels, i.e., national, state, local (Koppenjan and Klijn 2004). The boundaries of these arenas may overlap, with the same actor participating in multiple forums. The participant is influenced by the norms and institutions of each forum.

Forums are of particular interest for multilevel governance frameworks because of their flexibility, noncontractual influence, and scope to address information in a form relevant for their members. The effective management of resources in complex systems requires an adaptive governance framework with access to: trustworthy information at an appropriate scale; a mechanism for dealing with conflict; the ability to induce institutional compliance (rules); the provision of infrastructure (physical, technical, and institutional); and an ability to support and encourage change (Dietz et al. 2003, Gunderson and Light 2006). It is likely that adaptation can be achieved more easily in a socioeconomic setting that is flexible and responsive to change (Dobes 2012). Managers and decision makers can use their knowledge of internal organizational dynamics and historical policy positions, as well as relationships between organizations, as a reference point to inform their position or stance. Factors influencing their decisions may include their understanding of interdependencies, rules (both informal and formal), and trust relations (Klijn 2007). These relationships operate across and within multiple levels.

\section{Research focus and aims}

We aim to identify the climate-related concerns of Australian local government and business organizations; to describe any actions they are taking in response to climate change; and to assess the role of forums, with a focus on multilevel governance, in supporting these activities. The comparison of local government and business is of interest because of the very different regulatory and institutional environments experienced by the two types of organizations. It is anticipated that organizational responses to climate change will be influenced by their active involvement or participation in professional forums such as conferences, meetings, and sector-specific working groups.

\section{METHOD}

Data on organizational responses to climate change and associated forums were collected via focus groups and semistructured interviews in two regions of Australia, the Hunter and Swan Canning, during 2011. The Hunter region is located on the east coast of Australia, with an area of 39,000 $\mathrm{km}^{2}$ and a population of approximately 1 million people. Although the Hunter catchment itself occupies a smaller area, our study included local government areas north and south of the catchment that participated in HCCREMS, the regional coordinator for environmental initiatives. The low lying coastal flats portion is particularly vulnerable to inundation (storm surges) and sea level rise. The Swan Canning catchment is located on the west coast of Australia, with an area of 2126 $\mathrm{km}^{2}$ and a population of 1.7 million people including the state capital, Perth (Australian Bureau of Statistics 2010). The South West region of the state adjoining the Swan River has been identified as a biodiversity hotspot (Australian Government Department of Sustainability Environment Water Population and Communities 2009) and an area vulnerable to the likely impacts of climate change given longterm rainfall decline (CSIRO and Australian Government Bureau of Meteorology 2012).

The regional level has been identified as the most appropriate level for effective strategic planning and climate adaptation decisions to be made (Smit and Pilifosova 2001, Cole and Watrous 2007, Bauriedl 2011). The Hunter and the Swan Canning regions were selected because climate projections indicate a likely decease in rainfall and increase in temperature of about one degree for each region in the short term, with escalating impacts into the future (National Economics 2007-2008). In addition, both regions are considered areas of major significance in their respective states, with a range of settlement types including urban, peri-urban, and agricultural/ rural and a diverse base of industrial activity. There is a significant degree of contestation in resource use, a diffuse settlement pattern, ongoing population growth, and significant investment in physical infrastructure. However, the regions face different climate challenges and reactions to those challenges can depend on state government policies.

\section{Focus groups}

The overall aim of the focus groups was to enhance local capacity for adaptation by working through climate change issues of importance to local governments with guidance from a climate change communication expert. Focus groups were chosen as an appropriate method for investigation because they allow participants to consider their own views, or in this instance the views of their organization, on climate change responses along with others (Patton 2002). Focus groups typically consist of homogenous groups because it allows for a focused exploration of a narrow topic (Patton 2002). One focus group was held with representatives from local government in each region. Local government organizations were selected for study because initial desktop investigations revealed that in both regions this level of government was already responding to climate change. Recruitment took place via telephone contact with all local governments in the regions to invite an appropriate representative. A total of 24 participants attended the focus groups, 12 from each region, representing 6 different councils from the Hunter, out of a possible 14, and 12 councils from the Swan, out of a possible 31.

The focus groups did not follow the typical group interview style procedure. Instead the agenda included a series of presentations as well as guided group discussions of climate 
change issues and organizational responses. The latter were nominated by participants. This approach enabled the researchers to give some potentially valuable information back to participants in exchange for their contribution to the research project as an aid to two-way learning. With the focus on communication, many of the complex relationships surrounding climate adaptation were identified and discussed. The presentations included local on-ground examples of material drawn from the most recent scientific literature and allowed participants to share what they had learnt. Discussions were recorded and supplemented with notes and observations taken by members of the project team and nominated scribes during group activities. Lecture and workshop direction material was removed from this data, which was then coded according to emergent themes.

\section{Semistructured interviews}

Semistructured interviews were conducted with representatives from a selection of organizations in each region to gain insight into their organizations' responses to climate change. This data collection format allows for the same interview guide to be followed with each participant, while allowing freedom for the interviewer and the participant to engage in a conversation (Patton 2002). A comprehensive database was created for each region with organizations from different sectors for example, mining, agriculture, and construction, of different size: large (more than 200 employees), medium (between 200 and 20 employees), small (less than 20 employees), and that were public or private organizations. A purposeful sampling strategy was employed with the aim of including organizations from different sectors in each region. Recruitment took place via telephone contact with organizations to invite the most senior person responsible for climate change or environmental management activities to take part in an interview at their convenience.

Of the 24 interviews conducted, 12 were conducted in the Hunter and 12 in the Swan. Table 1 shows the number of participants interviewed from each organizational sector. Despite aiming to sample organizations from the same sectors in each region, the reality of participant availability meant that this was not possible. Also, although the diversity of sectors represented was reasonable, there were limitations to the range given the sample size. Interviews were conducted face to face, with the exception of four telephone interviews, and generally lasted for an hour. Through the semistructured format, participants were invited to discuss a range of topics including regional identity; the impact of climate change on their organization; familiarity with and use of terms associated with climate change, e.g., adaptation, mitigation, adaptive capacity; governance arrangements; strategic planning and approaches to risk, uncertainty, and decision making; and participation in formal or informal forums or industry discussion groups. All interviews were recorded, with participant permission, and notes taken by either the interviewer or in some instances by a second researcher. Transcripts were created with a unique code to ensure participant anonymity. A thematic analysis of transcripts was conducted with broad question headings used as guides. A summary document was created and sent back to participants to ensure the interpretation and reporting of interview data by researchers was correct.

Table 1. Semistructured interview participants by organizational sector.

\begin{tabular}{llll}
\hline \hline Hunter Region & & Swan Region & \\
\hline Agriculture & 1 & Agriculture & 2 \\
Construction & 2 & Communication & 1 \\
Manufacturing & 1 & Construction & 2 \\
Mining & 1 & Insurance & 1 \\
Retail & 3 & Mining & 1 \\
Services & 2 & Retail & 2 \\
Transportation & 1 & Services & 1 \\
Utilities & 1 & Transportation & 2 \\
Total n & 12 & Total n & 12 \\
\hline
\end{tabular}

\section{RESULTS}

\section{Local government perspectives}

At the beginning of the focus groups, participants were asked to nominate the most important climate change issue they were facing (see Table 2). The participants and the facilitator then categorized issues into broad topics to be addressed throughout the day in small group discussions.

For the local governments represented, the notion of building relationships and communication was strongly connected to adaptation planning and policy. Participants wanted to understand the importance of the networks in which they were already embedded, including links with the state level local government associations and Regional Organizations of Councils (ROCs), and to establish avenues to further utilize these connections with other tiers of government. For local governments in the Swan this manifested mostly in terms of connecting with state government. To effectively communicate with those outside their local government sector, participants suggested that relevant government departments and their key players needed first to be identified, and then an effort made to get to know these key players by inviting them to specific events aimed at collaboration and discussion around climate change issues, planning, and policy.

Rather than waiting for these multilevel interactions to take place, participants suggested that they needed to be strategic and prioritize collaboration. It was suggested that local government should initiate collaborations and work to continually improve relationships. Hunter participants suggested that to foster climate change awareness it was important to invite business and community to engage with local government through frequent interactions with the aim 
Table 2. Important climate change issues for local government (LG) identified by focus groups.

\begin{tabular}{|c|c|}
\hline Hunter Region & Swan Region \\
\hline $\begin{array}{l}\text { Community and Creating Awareness } \\
\text { - Climate change adaptation policy and planning. } \\
\text { - Balance between 'duty of care' and maintaining existing } \\
\text { 'lifestyles'. } \\
\text { Sea Level Rise } \\
\text { - Coastal Adaptation. } \\
\text { - Need for immediate decisions on action for } \\
\text { communities affected by sea level rise. } \\
\text { - Sea level rise and impacts on flooding. } \\
\text { Extreme Events/Natural Hazards/Environment } \\
\text { - Impacts on the natural environment. } \\
\text { - Extreme events causing heat waves and flooding. }\end{array}$ & $\begin{array}{l}\text { Transportation } \\
\text { - Transport routes during emergency events. } \\
\text { - Impacts on river foreshore - erosion, infrastructure damage, } \\
\text { impacts on recreation. } \\
\text { - Car dominance: investigating other transport options and behavior } \\
\text { change. } \\
\text { Water Security/Addressing Drought } \\
\text { - Drying climate, less rainfall. } \\
\text { - Drought and sinking groundwater tables. } \\
\text { - Maintaining parks and reserves with reduced water availability. } \\
\text { Communicating with residents about necessary changes to these } \\
\text { areas. } \\
\text { Internal Collaboration/Communication } \\
\text { - Compiling specific adaptation plans at the local level. } \\
\text { - Difficulty communicating climate adaptation needs of the local } \\
\text { government sector, e.g., policies, guidelines, funding. } \\
\text { Sea Level Rise } \\
\text { - Limited coastal geomorphology (rock/sand) data/information, } \\
\text { affecting ability to determine sea level rise and coastal impacts. } \\
\text { - Sea level rise and impacts on the Canning River. } \\
\text { - Rising sea levels and loss of coastal infrastructure. }\end{array}$ \\
\hline
\end{tabular}

of protecting jobs, the local economy, and to stimulate innovation. However, as noted by one participant, initiating and maintaining these connections was difficult because councils have a responsibility to share information but they do not necessarily know how to share it and respond to community queries. Delving deeper into comments such as these highlighted gaps in the skill set of staff on the front line that interact frequently with the public. Concern in this instance was not about the availability of information but rather participants were eager for any guidance on the most appropriate and effective ways to approach climate change topics with local communities particularly those that deal with likely changes in planning policies and initiatives to encourage and promote climate adaptation.

The complexity of multilevel governance arrangements, particularly in relation to topical issues such as the impact of sea level rise in coastal communities, was a common issue for both regions and has been documented in other case studies in Australia (see Abel et al. 2011). Of prime concern for both groups was the need to deliver messages about the potential negative impacts of sea-level rise to a mixed audience. Both groups suggested that involving many different stakeholders was one way to help improve communication and to establish working relationships. For example, Swan participants wanted to develop specific programs with target audiences with the inclusion of scientists to help with technical questions. Hunter participants focused on the need to preserve community values, suggesting that linking with community groups could help to inform their own actions.

Issues with difficult and conflicted power sharing relationships were raised by Swan local governments in relation to shared authority for a sustainable transport system. Specifically, they identified friction between groups, particularly aligning political and community goals; conflicts of worldviews and priorities; and lack of trust as pertinent issues. Although it has been recognized in the literature that effective adaptive governance frameworks need a mechanism for managing conflict (Dietz et al. 2003), many of those involved in these conflicts at the local government level may be unaware of the problem-solving capabilities they possess. Focus group discussions provided participants with the opportunity to go through several typical problem and conflict resolution processes. A variety of creative ideas to address problems were suggested by those in the sustainable transport discussion group, such as building relationships with involved parties separately at the beginning, then bringing them together in a nonthreatening environment.

As well as identifying the importance of external relationships, participants recognized that understanding the internal structure of local government was vital for addressing many climate related issues. For example, participants described how coping with drought required attention to both internal 
and external relationships. Internally, all members of council needed to be aware of circumstances, particularly the parks and gardens workers. Externally, contact with industry organizations was important to change, and careful engagement with community members was necessary to dissuade erroneous perceptions such as beliefs that parks were less green because local government (council) were not doing their job.

\section{Business perspectives}

The majority of organizations interviewed were small to medium-sized enterprises, although several had 1000 or more employees and another was a large public multinational company. Although some organizations found it difficult to place themselves in a regional context, most identified an area of operation within a radius of up to 100 kilometers, although larger companies had more of a national or international focus. Most respondents demonstrated a high level of awareness about company policies regarding governance and organizational values. Clarity about individual roles and reporting lines was particularly evident, with a clear understanding of the company's business model and focus.

However, in general, concern for climate change issues was overshadowed by issues relating to energy. Climate issues were most frequently framed around sustainability, rather than the terminology frequently used in the scientific literature, such as adaptation and mitigation. Most of the sustainability actions undertaken centered on environmental issues including waste management, recycling, fuel efficiency, asset replacement, and infrastructure management. At the time of the interviews in late 2011, many companies expressed concern and uncertainty about the likely impact of the new Clean Energy Future legislation. In addition, respondents made the often repeated observation that there was a lack of guidance from state and federal government on the interpretation of climate change policy, how it might be implemented, financial liability, and the potential impact on business operations. This issue was identified as a significant barrier in the conceptualization of strategies to address potential impacts and take advantage of opportunities. Many organizations expressed the opinion that they were not sure how to act, with some adopting a 'wait and see' approach.

\section{Role of forums in business and local government organizations}

Involvement in forums or industry groups was seen as essential by most participants in the interviews as a source of trusted information; to stay in touch with the activities and business practices of their competitors; to maintain up to date knowledge of standards and other applicable regulations and guidelines; and to share lessons across the sector. The value of these gatherings was considered high regardless of whether they were formal or informal, internal or external. The number of participants who did not take part in forums on behalf of their organization was very low, with most actively seeking involvement; and some holding official, elected positions and establishing internal committees to pass on knowledge. For those who lacked these opportunities, there was recognition that it would be beneficial to work on improving connections. Some noted that they were aware of committees and meetings but these were operating at other locations. One participant noted that forums dealing specifically with climate change and other environmental issues had existed but had been disbanded due to lack of tangible goals and difficulty in maintaining member participation.

Over 50 forums were identified by participants involved in the interviews, and although very few focused specifically on climate issues alone, many industry groups spent time discussing climate change and its relevance and impact on the sector. For example, some forums were connected to formal government schemes such as the NSW state government sustainability advantage program. Others had informal linkages with people in similar roles. Many participants stated that they did not participate in any climate change related forums but then went on to discuss various disaster management and sustainability-focused forums with which they were involved, that covered integrated issues. Others noted the importance of internal working groups and the internet in preparing them for their work. Some took part in international forums with a specific focus on sustainability, change management, and knowledge transfer, either privately or on behalf of their organization. Forums also differed in regard to size and formality, with some emerging directly in response to issues and others existing as an artifact or legacy of other actions.

The interviews indicate that there are numerous existing and potential avenues in which climate change issues could be addressed. Participants thought that industry association discussions would soon include climate change. The leadership demonstrated by these participants supports the contention that "the system vulnerabilities created by climate change can turn into 'systems opportunities' for businesses to develop novel partnerships with government, other players in the supply chain, and even traditional competitors, for example in preparing the infrastructure needed for disaster recovery" (Schwartz 2007:4).

Local governments appeared to have many forums in which climate change issues were discussed, including some specifically focused on climate adaptation. Regional Organization of Councils (ROCs) present in both regions provided an avenue for climate-focused activity, despite different state government policy positions. ROCs typically feature voluntary membership by local councils in bordering geographic areas, a board or some governing body, a memorandum of understanding between councils, agreed objectives, and in-kind contributions from councils (Gooding 
2012). Regional strategic planning and collaboration are the main goals for the formation of ROCs so it is no surprise that they provide important avenues for the development of climate change related initiatives. Participants provided examples of the role of these groups. The Western Suburbs Regional Organization of Councils (WESROC) is a collaboration of seven local councils in the Swan region. As a result of a study commissioned by WESROC, a Climate Change Risk Assessment and Adaptation Plan was developed (Coastal Zone Management 2010). In partial fulfillment of the plan, an adaptation workshop was held in which over 30 adaptation options were identified and assigned to the responsibility of either WESROC or individual council departments. Similarly, on the east coast, the HCCREMS embarked on a program to raise awareness of the regional impact of climate change sponsoring research that was later presented to participating councils to help them develop strategies to address these impacts (Verdon and Goodwin 2007, Blackmore and Goodwin 2008, 2009).

Despite the mixture of different local councils present at the focus groups, they all appeared to face similar types of climate change related issues. As a consequence, the focus group convener suggested that the expertise and experience represented by the attendees should be utilized in additional local government forums. The benefits of bringing together diverse councils meant that despite a similarity in issues, responses were varied with opportunities for sharing lessons about alternative, tried and tested approaches. Feedback from participants indicated that these opportunities were highly regarded and appreciated.

\section{DISCUSSION}

\section{Potential for maximizing the strengths of regional organizations for climate adaptation}

Our results indicate that organizations possess latent capacities and resources that are invaluable in developing and implementing strategic responses to climate change. The focus group outcomes are consistent with the ideas of social learning or observational learning utilized in substantive research on collective approaches to complex environmental management (Kilvington 2007, Steyaert and Jiggins 2007, Berkes 2009). There are active personal and professional networks in place that have been built up by repeated interactions over many years. Organizational representatives are involved in multiple forums with members that account for a diverse set of organizations and that possess a range of skills, experience, resources, motivations, and aspirations. These capacities represent collective assets that could be utilized in coordinated and well-articulated climate adaptation initiatives. A further benefit of such strategies is the potential for inter- and intraorganizational learning and mainstreaming. Several respondents noted that they appreciated the scheduling of meetings dedicated to climate change issues at forums they attended, because generally experts were available to respond to questions and gave presentations that were focused on the industry offering practical advice.

However, the need for highly developed communication skills, leadership, and access to expert guidance was highlighted in this study. Problems range from identifying appropriate ways to communicate messages that are likely to be perceived as negative such as the potential impact of sea level rise on coastal properties, through to developing clear meeting agendas where the concerns and needs of forum members along with the potential benefits of participation are well articulated. An associated skill, the effective management of interactions, is important to ensure fairness and procedural justice even though total agreement is not a necessary prerequisite for success within either formal or informal forums. The idea of consensus has relevance in the discussion of collective governance of adaptation because of suggestions that agreement cannot be reached by a group whose members hold different preferences. This perspective on consensus or preference aggregation when all opinions are admissible is expressed in Arrow's impossibility theorem described by List (2002). However, a group can make consistent consensual judgements at a metalevel even though individual preferences may vary in multi-issue discussions. Elster (1986) calls this deliberation-induced agreement. Interaction in groups or forums provides opportunities for issue discussion and airing of disagreements and counterargument at the substantive level. The preferences of individuals who do not necessarily agree that climate adaptation responses are essential but who will still be impacted by changes that may occur are accounted for in this research by ensuring that they have equal opportunity to express their opinions in forums and that their concerns are given equal treatment and consideration in discussions and decision making.

Responding to climate change requires a high level of strategic planning to ensure that institutional and legal structures are in place, particularly to support adaptive practices (Blanco et al. 2009, Bedsworth and Hanak 2010). This planning needs to occur at multiple levels of governance to ensure that it is effective, and opportunities to nest short-term decisions on infrastructure for example into longer term frameworks should be encouraged (Stafford-Smith et al. 2011). The respondents in the semistructured interviews asserted that it was difficult for their organization to undertake strategic planning for climate change because of the pressures of operating in a highly competitive environment characterized by narrow margins and uncertainty.

Cross-scale and cross-level dynamics (Cash and Moser 2000, Cash et al. 2006) among interviewees is exemplified by interaction between different forums; for example, participants were involved in national industry standards committees as well as international forums looking at 
sustainability and climate change adaptation issues in developing nations. The networks developed through these interactions span regional, national, and global levels.

Our research shows that many organizations struggle to comply with the multilevel implications of decisions made at organizational head offices. These impacts were seen to cascade down to affect local offices with little autonomy. Thus, many processes interact and play out across scales of relevance to organizations. Underdal (2010) suggests that an appropriate governance system supporting the role of forums is one that combines the flexibility, diversity, and learning capacity of an adaptive governance model with the focus and sustained commitment of a collective action model, which is decentralized enough to provide opportunities for local initiatives as well as those operating at higher levels. This synergy needs to occur at the regional level to empower local action and support the development of collective thinking.

\section{CONCLUSION}

The research presented here indicates that forums provide opportunities to address a range of issues including climate change. Forums offer the requisite social infrastructure for successful meetings such as venue, established networks, and membership that makes them a safe and familiar environment to air differing opinions and concerns related to the likely impacts of climate change. In addition, forums with mixed agendas offer opportunities for participants to listen to a broad range of ideas that may help them in determining their own position on issues. Some forums in this study facilitated the development and implementation of climate adaptation strategies, for example, actively encouraging risk assessments and the adoption of climate adaptation actions because they served the organization well and offered some protection from severe impacts of climate change.

In contrast, forums also impeded organizations by reinforcing a norm of not responding in a proactive way to impending policy changes and a preference to "wait and see." Delaying action may avoid potentially expensive and maladaptive responses but an assessment of this nature requires careful consideration of options. Inaction may also prove prohibitive and lock groups into unintended futures. Planning decisions for climate adaptation and their future implications are complex, particularly given the many uncertainties.

The difference between forums that facilitate or impede adaptation actions may be due to the networks in which they are embedded and their specific structural properties. This requires further investigation, specifically to determine how structural features of networks constrain or enable effective climate change action. In addition the Ecology of Games paradigm (Long 1958, Scholz et al. 2008, Lubell et al. 2010), which investigates the objectives and rules that govern interaction, could be pursued in future studies. Questions of interest include, whether relationships become stronger over time, as members use forums as venues for seeking advice, building consensus, lobbying, providing normative guidance, and developing, reinforcing, and promoting protocols. Exploring the influence of forums on each other as these functions expand is also of interest.

Our findings suggest that more work is required to promote organizational engagement with climate change discourse, planning, and action. Although terms like climate adaptation, mitigation, adaptive capacity, and others common in scientific and policy discussion were not seen as relevant or appropriate for everyday use within organizations, this need not act as a barrier if plausible and practical steps to address climate change are communicated to organizations. Forums and networks can offer a practical avenue for conveying these ideas. In addition, forums can provide an opportunity to develop strategic plans that are characterized by mainstreaming policy, creating functional linkages between related issues that have the potential to increase the efficiency and effectiveness of policies (Kok and de Coninck 2007). Repeated interaction encourages sharing of common understandings of industry challenges, discussion of technological advances, reduction of uncertainty as a result of repeated exposure to strategizing, and negotiation enabling consensus and opportunities for alliance formation (Rosenkopf et al. 2001). Some of the larger multinational organizations included in our research demonstrated this approach to strategic planning. However, the need for expert guidance and ongoing training and support to facilitate communication and interactions within and between groups is fundamental to underpin these efforts. More research is required to understand how different types of organizations utilize forums to learn more about other organizational responses to climate change within their region, both in formal and informal settings.

Although numerous forums were being utilized in our study, an important next step is to gain an understanding of the effectiveness of forums for addressing climate change issues. Importantly the mention of disbanded sustainability forums during interviews provides some initial insight into unsuccessful forums. More investigation into the characteristics of successful and unsuccessful forums is particularly important if existing avenues are to be utilized for discussing and addressing climate change issues. The interaction of researchers and organizational stakeholders in the form of focus groups in this study could be considered an intervention for the purpose of future research. The two way learning environment supported the formation of relationships (networks) with the potential for forum initiation. It will be interesting to assess the robustness of these linkages and follow their progress as the research progresses via follow-up interviews with participants.

The findings of this research suggest that although many organizations prefer to take a risk management approach to 
climate change, uncertainty remains pervasive. Regardless, the concerted adoption of climate adaptation practices is imperative and overdue. At this stage adaptive actions by organizations and other agents in multilevel governance regimes in Australia are in most cases ad hoc and uncoordinated. Initiatives promoted and supported by local government appear to be the exception. The influence of groups such as the Sydney City Councils Group in the recognition of sea level rise in planning frameworks is a case in point (Measham et al. 2011). Addressing the implications of climate change is clearly an issue requiring collective action. The role of collaborative practice among organizations exemplified by networks and forums, both formal and informal, is largely undocumented, but we believe that these interactions are likely to play a significant role in organizational awareness, perception, and response to climate change issues at the local to regional level. We contend that forums constitute a level of governance deeply embedded in organizational practice that influences both their capacity and motivation to undertake climate adaptation.

Responses to this article can be read online at:

http://www.ecologyandsociety.org/issues/responses. php/6120

\section{Acknowledgments:}

The authors wish to acknowledge the support of the CSIRO Climate Adaptation Flagship in providing funding for this research effort as a strategic initiative. The participation and generosity of Dr Susan Moser who applied her enthusiasm and considerable expertise in climate change communication to act as the facilitator of the workshops is also acknowledged. Finally the comments and suggestions of two anonymous reviewers are highly appreciated.

\section{LITERATURE CITED}

Abel, N., R. Gorddard, B. Harman, A. Leitch, J. Langridge, A. Ryan, and S. Heyenga. 2011. Sea level rise, coastal development and planned retreat: analytical framework, governance principles and an Australian case study. Environmental Science \& Policy 14:279-288.

Agranoff, R. 2006. Inside collaborative networks: ten lessons for public managers. Public Administration Review 66:56-65. http://dx.doi.org/10.1111/j.1540-6210.2006.00666.x

Ansell, C., and A. Gash. 2008. Collaborative governance in theory and practice. Journal of Public Administration Research and Theory 18:543-571. http://dx.doi.org/10.1093/ jopart/mum032
Armitage, D. 2008. Governance and the commons in a multilevel world. International Journal of the Commons 2:7-32.

Australian Bureau of Statistics. 2002. Small business in Australia 2001. Australian Bureau of Statistics, Canberra, Australia.

Australian Bureau of Statistics. 2010. National regional profile 2006-2010. Australian Bureau of Statistics, Canberra, Australia.

Australian Government Department of Climate Change and Energy Efficiency. 2012b. Local Adaptation Pathways Program. Australian Government, Canberra, Australia. [online] URL: http://www.climatechange.gov.au/climatechange/adapting-climate-change/climate-change-adaptation-program/ local-adaptation-pathways

Australian Government Department of Climate Change and Energy Efficiency. 2012a. Low carbon communities. Australian Government, Canberra, Australia. [online] URL: http://www.climatechange.gov.au/lowcarboncommunities

Australian Government Department of Resources Energy and Tourism. 2012. About smart grid, smart city. Australian Government, Canberra, Australia. [online] URL: http://www. smartgridsmartcity.com.au/About-Smart-Grid-Smart-City.aspX

Australian Government Department of Sustainability Environment Water Population and Communities. 2009. Australia's 15 national biodiversity hotspots. Australian Government, Canberra, Australia. [online] URL: http://www. environment.gov.au/biodiversity/hotspots/national-hotspots.html

Australian Government Department of Sustainability Environment Water Population and Communities. 2012. Cities for Climate Protection (CCP) Australia. Australian Government, Canberra, Australia. [online] URL: http://www. environment.gov.au/archive/settlements/local/ccp/

Bache, I., and M. Flinders, editors. 2004. Multi-level governance. Oxford University Press, New York, New York, USA.

Baker and McKenzie. 2011. Local council risk of liability in the face of climate change - resolving uncertainties. A Report for the Australian Local Government Association. Baker and McKenzie, Melbourne and Sydney, Australia.

Bates, L. E., M. Green, and I. Walker. 2011. Strategic planning for collaborative practice: the potential for interorganisational cooperation to overcome constraints to climate adaptation. Local Government Researchers Forum: Local Governance in Transition. Australian Centre of Excellence for Local Government. University of Sydney, New South Wales, Australia. [online] URL: http://www.acelg.org.au/sites/ default/files/Climate\%20change\%20CSIRO.pdf 
Bauriedl, S. 2011. Adaptive capacities of European city regions in climate change: on the importance of governance innovations for regional climate policies. Pages 3-14 in W. Leal Filho, editor. The economic, social and political elements of climate change. Springer, Heidelberg, Germany. http://dx. doi.org/10.1007/978-3-642-14776-0 1

Bedsworth, L. W., and E. Hanak. 2010. Adaptation to climate change. Journal of the American Planning Association 76:477-495. http://dx.doi.org/10.1080/01944363.2010.502047

Berkes, F. 2009. Evolution of co-management: role of knowledge generation, bridging organizations and social learning. Journal of Environmental Management 90:1692-1702. http://dx.doi.org/10.1016/j.jenvman.2008.12.001

Berkhout, F. 2012. Adaptation to climate change by organizations. Wiley Interdisciplinary Reviews: Climate Change 3:91-106. doi:110.1002/wcc.1154. http://dx.doi. org/10.1002/wcc. 154

Bidwell, R. D., and C. M. Ryan. 2006. Collaborative partnership design: the implications of organizational affiliation for watershed partnerships. Society \& Natural Resources 19:827-843. http://dx.doi.org/10.1080/08941920600835585

Biondi, V., M. Frey, and F. Iraldo. 2000. Environmental management systems and SMEs. Greener Management International 29:55-69.

Blackmore, K. L., and I. D. Goodwin. 2008. Report 2: climate variability of the Hunter, Lower North Coast and Central Coast Region of NSW. Hunter and Central Coast Regional Environmental Management Strategy, and the University of Newcastle, Callaghan, Australia.

Blackmore, K. L., and I. D. Goodwin. 2009. Report 3: climatic change impact for the Hunter, Lower North Coast and Central Coast Region of NSW. Hunter and Central Coast Regional Environmental Management Strategy, and the University of Newcastle, Callaghan, Australia.

Blanco, H., M. Alberti, A. Forsyth, K. J. Krizek, D. A. Rodriguez, E. Talen, and C. Ellis. 2009. Hot, congested, crowded and diverse: emerging research agendas in planning. Progress in Planning 71:153-205. http://dx.doi.org/10.1016/ j.progress.2009.03.001

Brammer, S., S. Hoejmose, and K. Marchant. 2012. Environmental management in SMEs in the UK: practices, pressures and perceived benefits. Business Strategy and the Environment 21:423-434. http://dx.doi.org/10.1002/bse.717

Bulkeley, H., and S. C. Moser. 2007. Responding to climate change: governance and social action beyond Kyoto. Global Environmental Politics 7:1-10. http://dx.doi.org/10.1162/ glep.2007.7.2.1

Cash, D. W., W. N. Adger, F. Berkes, P. Garden, L. Lebel, P. Olsson, L. Pritchard, and O. Young. 2006. Scale and cross- scale dynamics: governance and information in a multilevel world. Ecology and Society 11(2): 8. [online] URL: http:// www.ecologyandsociety.org/vol11/iss2/art8/

Cash, D. W., and S. C. Moser. 2000. Linking global and local scales: designing dynamic assessment and management processes. Global Environmental Change 10:109-120. http:// dx.doi.org/10.1016/S0959-3780(00)00017-0

Coastal Zone Management. 2010. Western suburbs regional organisation of councils (WESROC) climate change risk assessment and adaptation plan: final report. Coastal Zone Management, Claremont, Western Australia. [online] URL: http://www.mosmanpark.wa.gov.au/library/file/Public documents/ WESROC Climate Change Risk Assessment and Adaptation Plan. pdf

Cole, N., and S. Watrous. 2007. Across the great divide: supporting scientists as effective messengers in the public sphere. Pages 180-199 in S. C. Moser and L. Dilling, editors. Creating a climate change: communicating climate change and facilitating social change. Cambridge University Press, Cambridge, UK. http://dx.doi.org/10.1017/CBO9780511535871.014

CSIRO and Australian Government Bureau of Meteorology. 2012. State of the climate 2012. Australian Government, Canberra, Australia.

Dietz, T., E. Ostrom, and P. C. Stern. 2003. The struggle to govern the commons. Science 302:1907-1912. http://dx.doi. org/10.1126/science.1091015

Dobes, L. 2012. Adaptation to climate change: formulating policy under uncertainty. Australian National University, Canberra, Australia.

Easterling, W. E., B. H. Hurd, and J. B. Smith. 2004. Coping with global climate change: the role of adaptation in the United States. Pew Centre on Global Climate Change, Arlington, Virginia, USA.

Elster, J. 1986. The market and the forum. Pages 103-132 in J. Elster and A. Hylland, editors. Foundations of social choice theory. Cambridge University Press, Cambridge, UK.

Fischlein, M., J. Larson, D. M. Hall, R. Chaudhry, T. R. Peterson, J. C. Stephens, and E. J. Wilson. 2010. Policy stakeholders and deployment of wind power in the subnational context: a comparison of four U.S. states. Energy Policy 38:4429-4439. http://dx.doi.org/10.1016/j.enpol.2010.03.073

Folke, C., T. Hahn, P. Olsson, and J. Norberg. 2005. Adaptive governance of social-ecological systems. Annual Review of Environment and Resources 30:441-473. http://dx.doi. org/10.1146/annurev.energy.30.050504.144511

Gooding, A. 2012. A comparative analysis of regional organisations of councils in NSW and Western Australia. Australian Centre of Excellence for Local Government, University of Technology, Sydney, Australia. 
Government of Western Australia Department of Environment and Conservation. 2012. Low emissions energy development fund. Government of Western Australia, Perth, Australia. [online] URL: http://www.dec.wa.gov.au/ourenvironment/climate-change/low-emissions-energy-developmentleed-fund.html

Gunderson, L., and S. Light. 2006. Adaptive management and adaptive governance in the everglades ecosystem. Policy Sciences 39:323-334. http://dx.doi.org/10.1007/s11077-006-9027-2

Gurran, N., B. Norman, C. Gilbert, and E. Hamin. 2011. Planning for climate change in Coastal Australia: state of practice. Report No. 4, Faculty of Architecture, Design and Planning, University of Sydney, Sydney, Australia.

Hunter Central Coast Regional Environmental Management System (HCCREMS). 2012. Climate change program overview. HCCREMS, Thornton, New South Wales, Australia. [online] URL: http://www.hccrems.com.au/ Programs/Climate-Change/Climate-Change-Overview.aspx

Intergovernmental Panel on Climate Change (IPCC). 2001. Climate change 2001: synthesis report. R. T. Watson and Core Writing Team, editors. Contribution of Working Groups I, II and III to the Third Assessment Report of the Intergovernmental Panel on Climate Change. Cambridge University Press, Cambridge, UK.

Kilvington, M. 2007. Social learning as a framework for building capacity to work on complex environmental problems. Landcare Research, Lincoln, New Zealand. [online] URL: http://www.landcareresearch.co.nz/publications/researchpubs/ Social_learning_review.pdf

Klijn, E. H. 2007. Managing complexity: achieving the impossible? Journal for Critical Policy Analysis 1:252-277.

Knuppe, K., and C. Pahl-Wostl. 2011. A framework for the analysis of governance structures applying to groundwater resources and the requirements for the sustainable management of associated ecosystem services. Water Resources Management 25:3387-3411. http://dx.doi.org/10.1007/ s11269-011-9861-7

Kok, M. T. J., and H. C. de Coninck. 2007. Widening the scope of policies to address climate change: directions for mainstreaming. Environmental Science and Policy 10:587-599. http://dx.doi.org/10.1016/j.envsci.2007.07.003

Koppenjan, J., and E. H. Klijn. 2004. Managing uncertainties in networks: a network approach to problem solving and decision making. Routledge, New York, New York, USA.

List, C. 2002. Two concepts of agreement. Good Society 11:72-79. http://dx.doi.org/10.1353/gso.2002.0011

Long, N. 1958. The local community as an ecology of games. American Journal of Sociology 64:251-261. http://dx.doi. org/10.1086/222468
Lubell, M., A. D. Henry, and M. McCoy. 2010. Collaborative institutions in an ecology of games. American Journal of Political Science 54:287-300. http://dx.doi.org/10.1111/ j.1540-5907.2010.00431.x

Maggioni, E., H. Nelson, and D. A. Mazmanian. 2012. Industry influence in stakeholder-driven state climate change planning efforts. Policy Studies Journal 40:234-255. http://dx. doi.org/10.1111/j.1541-0072.2012.00451.X

Matthews, R., and R. Sydneysmith. 2010. Adaptive capacity as a dynamic institutional process: conceptual perspectives and their application. Pages 223-242 in D. Armitage and R. Plummer, editors. Adaptive capacity and environmental governance. Springer, Heidelberg, Germany. http://dx.doi. org/10.1007/978-3-642-12194-4 11

Measham, T. G., B. L. Preston, T. F. Smith, C. Brooke, R. Gorddard, G. Withycombe, and C. Morrison. 2011. Adapting to climate change through local municipal planning: barriers and challenges. Mitigation and Adaptation Strategies for Global Change 16:889-909. http://dx.doi.org/10.1007/ s11027-011-9301-2

Moser, S. C. 2009. Whether our levers are long enough and the fulcrum strong? Exploring the soft underbelly of adaptation decisions and actions. Pages 313-334 in W. N. Adger, I. Lorenzoni, and K. L. O'Brien, editors. Adapting to climate change: thresholds, values, governance. Cambridge University Press, Cambridge, UK. http://dx.doi.org/10.1017/ CBO9780511596667.021

National Economics. 2007-2008. State of the regions 2007-08. Australian Local Government Association, Clifton Hill, Australia.

New South Wales Government Department of Environment and Heritage. 2012. Sustaining our Environment Climate Change Fund. New South Wales Government, Sydney, Australia. [online] URL: http://www.environment.nsw.gov. au/grants/ccfund.htm.

Paavola, J. 2008. Science and social justice in the governance of adaptation to climate change. Environmental Politics 17:644-659. http://dx.doi.org/10.1080/09644010802193609

Pahl-Wostl, C. 2009. A conceptual framework for analysing adaptive capacity and multi-level learning processes in resource governance regimes. Global Environmental Change 19:354-365. http://dx.doi.org/10.1016/j.gloenvcha.2009.06.001

Pahl-Wostl, C., L. Lebel, C. Knieper, and E. Nikitina. 2012. From applying panaceas to mastering complexity: toward adaptive water governance in river basins. Environmental Science \& Policy 23:24-34. http://dx.doi.org/10.1016/j. envsci.2012.07.014

Patton, M. Q. 2002. Qualitative research and evaluation methods. Third edition. Sage, Thousand Oaks California, USA. 
Reed, M. G., and S. Bruyneel. 2010. Rescaling environmental governance, rethinking the state: a three-dimensional review. Progress in Human Geography 34:646-653. http://dx.doi. org/10.1177/0309132509354836

Rosenkopf, L., A. Metiu, and V. P. George. 2001. From the bottom up? Technical committee activity and alliance formation. Administrative Science Quarterly 46:748-772. http://dx.doi.org/10.2307/3094830

Scholz, J. T., R. Berardo, and B. Kile. 2008. Do networks solve collective action problems? Credibility, search, and collaboration. Journal of Politics 70:393-406. http://dx.doi. org/10.1017/S0022381608080389

Scholz, J. T., and C.-L. Wang. 2006. Cooptation or transformation? Local policy networks and federal regulatory enforcement. American Journal of Political Science 50:81-97. http://dx.doi.org/10.1111/j.1540-5907.2006.00171.x

Schwartz, P. 2007. Investing in global security. Harvard Business Review 85:26-28.

Scott, J., and C. Weston. 2011. The pitfalls and promises of climate adaptation planning. Australasian Journal of Environmental Management 18:73-87. http://dx.doi. org/10.1080/14486563.2011.583612

Smit, B., and O. Pilifosova. 2001. Adaptation to climate change in the context of sustainable development and equity. Chapter 18 in J. J. McCarthy, O. F. Canziani, N. A. Leary, D. J. Dokken, and K. S. White, editors. Climate change 2001: impacts, adaptation and vulnerability. Contribution of Working Group II to the Third Assessment Report of the Intergovernmental Panel on Climate Change. Cambridge University Press, Cambridge.

Smith, T. F., D. C. Thomsen, and N. Keys. 2011. The Australian experience. Pages 69-84 in J. D. Ford and L. Berrang-Ford, editors. Climate change adaptation in developed nations: from theory to practice. Springer, Dordrecht, Netherlands.

Stafford-Smith, M., L. Horrocks, A. Harvey, and C. Hamilton. 2011. Rethinking adaptation for a 4 degrees C world. Philosophical Transactions of the Royal Society A: Mathematical Physical and Engineering Sciences 369:196-216. http://dx.doi.org/10.1098/rsta.2010.0277

Steyaert, P., and J. Jiggins. 2007. Governance of complex environmental situations through social learning: a synthesis of SLIM's lessons for research, policy and practice. Environmental Science and Policy 10:575-586. http://dx.doi. org/10.1016/j.envsci.2007.01.011
Studer, S., S. Tsang, R. Welford, and P. Hills. 2008. SMEs and voluntary environmental initiatives: a study of stakeholders' perspectives in Hong Kong. Journal of Environmental Planning and Management 51:285-301. http:// dx.doi.org/10.1080/09640560701865073

Underdal, A. 2010. Complexity and challenges of long-term environmental governance. Global Environmental Change 20:386-393. http://dx.doi.org/10.1016/j.gloenvcha.2010.02.005

Verdon, D., and I. D. Goodwin. 2007. Progress report 1 to HCCREMS on Stage 1 of the regional climate change study. Hunter and Central Coast Regional Environmental Management Strategy, and the University of Newcastle, Callaghan, Australia.

Western Australian Local Government Association (WALGA). 2012. Climate change management toolkit. WALGA, Perth, Australia. [online] URL: http://www. walgaclimatechange.com.au/

Whitmarsh, L., and I. Lorenzoni. 2010. Perceptions, behavior and communication of climate change. Wiley Interdisciplinary Reviews: Climate Change 1:158-161. http://dx.doi. org/10.1002/wcc.7

Winn, M. I., M. Kirchgeorg, A. Griffiths, M. K. Linnenluecke, and E. Gunther. 2011. Impacts from climate change on organizations: a conceptual foundation. Business Strategy and the Environment 20:157-173. http://dx.doi.org/10.1002/ bse. 679 